\title{
A SEDUÇÃO DA AUSÊNCIA: O TEXTO E A EPISTEMOLOGIA DA CIÊNCIA
}

\author{
Ana FUKUI ${ }^{1}$ \\ Maria Eduarda GIERING ${ }^{2}$
}

\begin{abstract}
Resumo: O objetivo deste estudo é mostrar como o produtor textual organiza, em artigos de divulgação científica para crianças da revista Ciência Hoje das Crianças (CHC), a passagem do senso comum para o saber científico. Para isso, estudam-se, tendo por base a Análise Textual dos Discursos, o título e os parágrafos iniciais dos artigos, observando como acontecem a instalação do tópico discursivo, a construção de objetos de discurso e a orientação argumentativa. A análise linguística proposta é iluminada pelos princípios da Epistemologia da Ciência, de Bachelard, que orientam o produtor-divulgador da ciência. Observa-se que o texto se organiza de forma a desencadear um processo de orientação argumentativa que parte de um saber comum à instalação do saber científico, base do fim discursivo de incitação ao fazer, comum aos artigos do corpus. Verifica-se que a CHC busca aproximar o conteúdo científico de seus leitores, ao criar estratégias para uma efetiva apropriação do conhecimento por meio da crítica ao senso comum e do estabelecimento do conceito científico.
\end{abstract}

Palavras-chave: Divulgação científica. Crianças. Orientação argumentativa. Ciência Hoje das Crianças. Epistemologia da ciência.

\section{Introdução}

O tema da divulgação científica para crianças é bastante abrangente, sendo estudado por cientistas de diversas áreas, como a Ciência da Comunicação, a Linguística Discursiva e o Ensino de Ciências. Embora com objetivos diferentes, esses estudos têm em comum a revelação da importância do tema, uma vez que a curiosidade

\footnotetext{
${ }^{1}$ UNISINOS - Universidade do Vale do Rio do Sinos - Programa de Pós-Graduação em Linguística Aplicada. São Leopoldo - Rio Grande do Sul - Brasil. 93022-000 - anafukui@ hotmail.com

${ }^{2}$ UNISINOS - Universidade do Vale do Rio do Sinos - Programa de Pós-Graduação em Linguística Aplicada. São Leopoldo - Rio Grande do Sul - Brasil. 93022-000 - eduardajg@ gmail.com
} 
infantil faz desse público um destinatário natural da divulgação científica/popularização da ciência ${ }^{3}$. Acerca da divulgação científica para as crianças, Massarani (2008, p. 8) afirma:

\begin{abstract}
Sistematicamente, elas tentam entender como as coisas funcionam e como é o mundo a sua volta. Além disso, experiências educacionais vêm demonstrando que o público infantil tem grande capacidade de lidar com temas de ciência. No entanto, acreditamos que essa capacidade não tem sido explorada em sua plenitude, especialmente em um espaço fora da educação escolar. Acreditamos que a divulgação científica bem feita pode ser um instrumento útil para a consolidação de uma cultura científica na sociedade.
\end{abstract}

Tendo isso em vista, este artigo foca a divulgação científica destinada ao público infantil publicada na revista Ciência Hoje das Crianças (doravante CHC) sob a perspectiva da Análise Textual dos Discursos (doravante ATD), conforme Adam (2011), e da concepção de contrato de midiatização da ciência, de acordo com a proposta de Charaudeau (2010), ou seja, como um discurso com uma dupla finalidade, a de informar e, ao mesmo tempo, a de captar o leitor. A análise do corpus busca marcas linguísticas da passagem do discurso do senso comum para o discurso da ciência, baseando-se em princípios da ATD, que oferece subsídios para o estudo da superfície de textos.

A CHC, considerando-se as revistas brasileiras de divulgação científica para o público infantil, possui características peculiares, pois trata de temas exclusivamente voltados para a ciência e muitas de suas matérias são escritas por cientistas, enquanto que, nos demais veículos, como a revista Recreio e a Coquetel, os assuntos são os mais diversos - tecnologia, sugestões de brincadeiras, personagens de programas televisivos, caça-palavras, palavras cruzadas etc. - e os responsáveis pela redação dos textos são jornalistas.

A esse respeito, ressalta-se que o fato de os cientistas atuarem como autores desses artigos é significativo do ponto de vista enunciativo e argumentativo, pois essa identidade confere ao produtor uma competência para dizer. Sua fala está investida da força do discurso da ciência, o que a legitima.

\footnotetext{
${ }^{3}$ Neste artigo, não se faz distinção entre os dois termos.
} 
O corpus de textos selecionado para análise é formado por 30 artigos de fim discursivo fazer-fazer, que embasaram pesquisa anterior de Giering (2016) sobre a presença do discurso promocional em artigos da CHC. O discurso chamado de promocional, conforme Charaudeau (2010), é um dos tipos do discurso propagandista, que se caracteriza por uma incitação ao fazer. O estudo de Giering (2016) revelou que os textos da CHC, de fim discursivo fazer-fazer, tinham o intuito de, por meio da divulgação científica midiática, provocar ações que beneficiassem os destinatários e de valorizar o saber cientifíco ao estabelecer relações entre ciência e vida social.

Neste artigo, o enfoque sobre os textos desse corpus é outro, já que se busca verificar a passagem do discurso do senso comum para o discurso científico, observando esse evento também sob a perspectiva da Epistemologia da Ciência, segundo as proposições de Bachelard (1996). Acredita-se que essa abordagem possa contribuir para esclarecer o movimento argumentativo do produtor dos textos, que aposta em uma aproximação com o leitor e negocia com este um ponto de partida comum acerca do tópico que será abordado no artigo, a fim de levar ao fazer. Assim, como a negociação com o leitor em relação às concepções que este traz para o texto acontece na parte inicial dos artigos - título, subtítulo e primeiro e/ou segundo parágrafo -, concentrou-se o estudo nesses itens, para que fosse possível mostrar o movimento argumentativo presente sob o enfoque da Epistemologia da Ciência.

\section{Fundamentos teóricos}

As relações sociais, de acordo com Charaudeau (2010), traduzem-se na linguagem como uma influência mútua entre os participantes a partir do princípio de alteridade, uma vez que ocorre o reconhecimento de si e do outro como sujeitos falantes e interativos. No entanto, esse processo também leva à percepção de diferenças, que podem ser interpretadas como uma espécie de ameaça, exigindo de seus interlocutores a resolução do conflito.

No discurso propagandista, de forma geral, a ameaça é traduzida como ausência ou falta de algo. Particularmente no discurso promocional, essa falta é identificada como um comportamento desejado para a prevenção de danos à pessoa, tais como parar de fumar, praticar exercícios, realizar exames para a prevenção de doenças etc. 
Giering (2016) mostra que o discurso promocional na Divulgação Científica Midiática (doravante DCM) vai além da ideia de campanha de prevenção, é um dos tipos do discurso propagandista, que se caracteriza por uma incitação ao fazer. De acordo com a autora, "na DCM, se o locutor, baseado em conhecimentos científicos, apresenta uma falta ao leitor e o incita a um fazer que preenche o objeto de busca e o torna (ou a sociedade) beneficiário deste fazer, temos esse tipo de discurso" (GIERING, 2016, p. 65).

Trata-se da indicação de uma lacuna existente, seja de ação, seja de conhecimento, seguida de informações que permitem o preenchimento do espaço vazio. A mudança, nesse caso, é virtuosa, pois faz com que o aumento de informações contribua para o exercício da crítica da realidade e para o exercício da cidadania.

Nos textos em estudo, a falta ou lacuna se mostra pelo desconhecimento do leitor sobre algum tema da área de especialidade do cientista; sobre uma ação equivocada que costuma acontecer na sociedade, pela qual presumidamente o leitor também é responsável, como, por exemplo, dar comida para os animais em parques e matas urbanas; ou sobre um problema de ordem geral, como a mudança climática, que pode ser minimizada por uma ação individual com repercussão global.

Nos títulos e no início dos textos do corpus, por exemplo, observa-se o primeiro movimento do percurso discursivo do produtor, que apresenta o tópico do discurso e negocia com o leitor a passagem do saber comum ao saber científico, cuja posse o tornará apto ao fazer. Ao se analisarem os textos para compreender como acontece esse percurso discursivo, estudam-se as marcas linguísticas que assinalam a inserção do tópico discursivo, a construção do objeto de discurso e a orientação argumentativa. Para isso, recorrem-se às categorias da Linguística Textual (doravante LT) e da Análise Textual dos Discursos (doravante ATD).

A noção de tópico discursivo (KOCH, 2014; MARCUSCHI, 2006; JUBRAN, 2011; CAVALCANTE; CUSTÓDIO FILHO; BRITO, 2014) diz respeito ao assunto tratado em determinado trecho do texto, sobre o qual se concentram, de forma dominante e relevante, os elementos desse trecho, dando coerência ao texto. Os segmentos iniciais dos artigos analisados apresentam o tema de que eles tratam. Em geral, esse tópico é manifestado por meio de uma expressão nominal que acaba sendo recategorizada à medida que a orientação argumentativa do texto se desloca do senso 
comum para o saber científico. Trata-se, aqui, do fenômeno da referenciação, que, conforme Cavalcante, Custódio Filho e Brito (2014), seguindo Mondada e Dubois (1995), mostra o caráter altamente dinâmico do processo de construção dos referentes em um texto. Os objetos de discurso ou referentes (APOTHÉLOZ; REICHLERBÉGUELIN, 1995) são construídos discursivamente. Conforme Koch (2009, p. 61), “o sujeito, por ocasião da interação verbal, opera sobre o material linguístico que tem à sua disposição, procedendo a escolhas significativas para representar estados de coisas, com vistas à concretização de sua proposta de sentido".

A construção e a recategorização dos objetos de discurso ocorrem à medida que acontece a progressão/continuidade temática, ou seja, "o avanço do texto por meio de novas predicações sobre os elementos temáticos (dados ou inferíveis do contexto)" (KOCH, 2008, p. 123). Na análise dos trechos dos artigos da CHC, foca-se a progressão textual sob a perspectiva da noção de orientação argumentativa, conforme propõe Adam (2011). Para o linguista, "todo enunciado possui um valor argumentativo, mesmo uma simples descrição desprovida de conectores argumentativos" (ADAM, 2011, p. 122). Assim, para além da continuidade referencial, observa-se, nos trechos selecionados, o movimento argumentativo marcado (ou não) por conectores. Objetiva-se, analisando os trechos a partir dessas categorias, explicitar o fazer discursivo do produtor para realizar a passagem da concepção de senso comum para o saber científico.

Para complementar tal abordagem, é elucidativo entender como esse percurso discursivo é também subsidiado por um enfoque epistemológico. Uma das principais preocupações da Epistemologia da Ciência é explicar os fundamentos do conhecimento científico, que, durante muito tempo, era visto como exclusivamente racional. Tal ideia, contudo, foi desmontada ao longo do século XX por pensadores como Karl Popper (2006), que demonstrou a possibilidade de provar a falseabilidade de um argumento, mas nunca sua veracidade plena. Outro foco de investigação da Epistemologia girou em torno dos processos de organização da comunidade científica e de seus pressupostos; nessa linha, destaca-se o famoso trabalho de Thomas Kuhn (1992) sobre as revoluções científicas e o estabelecimento de um paradigma. Nesse contexto, descreveu-se como os especialistas legitimam ou não seus saberes e suas proposições e evidenciou-se que muitas escolhas realizadas se apoiavam em outros critérios, além dos racionais. 
Gaston Bachelard, por sua vez, traz para o interior de sua análise epistemológica diversos fenômenos psicológicos que descrevem as etapas do conhecimento em ciências:

\begin{abstract}
Quando se procuram as condições psicológicas do progresso da ciência, logo se chega à convicção de que é em termos de obstáculos que o problema do conhecimento científico deve ser colocado. E não se trata de considerar obstáculos externos, como a complexidade e a fugacidade dos fenômenos, nem de incriminar a fragilidade dos sentidos e do espírito humano: é no âmago do próprio ato de conhecer que aparecem, por uma espécie de imperativo funcional, lentidões e conflitos. É aí que mostraremos causas de estagnação e até de regressão, detectaremos causas da inércia às quais daremos o nome de obstáculos epistemológicos (BACHELARD, 1996, p. 17).
\end{abstract}

O ponto de partida desse filósofo é bastante conciso - para o ser humano, conhecer implica um desordenamento de sua essência, que, como tal, é acompanhado de resistências, de voltas ao estágio anterior e de tumultos internos. No entanto, tudo isso faz parte do processo de aprendizado e pode ser descrito por uma epistemologia que se preocupa mais com a formação de um “espírito científico" (BACHELARD, 1996, p.11) do que com a descrição dos fundamentos da ciência.

O conceito central apresentado por Bachelard (1996) é o de obstáculo epistemológico, uma categoria que sintetiza uma série de características do conhecimento científico e das resistências a sua transformação de acordo com cada momento histórico. Para o autor, a construção do conhecimento inicia com a constatação de uma dada realidade, chamada de experiência primeira: "a experiência colocada antes e acima da crítica" (BACHELARD, 1996, p. 29). São os conceitos, por assim dizer, que descrevem as ações cotidianas das pessoas, baseadas em experiências sensoriais. Na Física, o melhor exemplo de conceito que emerge da experiência direta é a afirmação de que os objetos pesados caem mais rápido que os objetos leves. No entanto, a partir dos estudos de Galileu, sabe-se que todos os objetos caem da mesma forma, porque estão sujeitos à mesma aceleração gravitacional. As alterações nesse comportamento ocorrem devido à presença de agentes externos à interação entre os dois corpos: o planeta Terra e o objeto em queda.

É muito comum chamar essa experiência primeira, que não passa por nenhuma reflexão ou crítica, de senso comum. Como se verá na análise dos trechos iniciais do 
corpus selecionado, parte deles começa com o estabelecimento do senso comum; a tarefa que surge a partir disso é trazer ponderações que mostrem os limites da experiência primeira e conduzam o leitor em direção ao conhecimento científico:

De fato, a objetividade científica só é possível se inicialmente rompemos com o objeto imediato, se recusamos a sedução da primeira escolha, se detemos e refutamos os pensamentos que nascem da primeira observação. Toda objetividade, devidamente verificada, desmente o primeiro contato com o objeto (BACHELARD, 1994, p. $1-2)$.

Portanto, a elaboração do conhecimento científico acontece a partir do primeiro contato com o objeto de estudo e da recusa da impressão inicial: nesse momento são estabelecidos diversos caminhos possíveis para a elaboração do saber. Trata-se do ponto de partida para a objetividade.

Essa aproximação não é, contudo, a única possível entre os dois campos. Há, ainda, a necessidade de explorar o motivo pelo qual se caminha em direção ao conhecimento científico, uma vez que se reconhece a dificuldade imposta por esse movimento.

A análise dos textos do corpus descreve de onde parte o produtor-divulgador e aonde ele deseja chegar, mas não explica o porquê desse deslocamento. Em relação a isso, a epistemologia bachelardiana propõe que:

Há no homem uma verdadeira vontade de intelectualidade. [...] Propomos, pois, agrupar sob o nome de complexo de Prometeu, todas as tendências que nos impelem a saber tanto quanto nossos pais, tanto quanto nossos mestres, mais que nossos mestres. Ora, é ao manipular o objeto, é ao aperfeiçoar nosso conhecimento objetivo que podemos esperar situar-nos mais claramente no nível intelectual que admiramos em nossos pais e em nossos mestres (BACHELARD, 1994, p. 18).

Reconhece-se, assim, que o saber para o homem é mais do que uma mera necessidade; trata-se, na verdade, de uma vontade primordial que se instala quando o outro é percebido como portador do conhecimento. Dentro dessa lógica, uma das figuras mais representativas da posse do saber na sociedade atual é a do cientista. Além disso, epistemologicamente, seu conhecimento é validado duplamente - como possuidor do que as pessoas desejam intelectualmente e como alguém que já passou pelas diferentes 
etapas do processo de aquisição do conhecimento científico. Sendo assim, ao escrever um texto de divulgação científica, o cientista tem a possibilidade de fornecer os apoios adequados para que a primeira impressão caminhe em direção à objetividade científica.

\section{Metodologia}

Os textos que compõem o corpus deste estudo foram publicados na $\mathrm{CHC}$ e pertencem a diversos gêneros discursivos. Todos têm o fim de incitação (fazer-fazer), ou seja, objetivam não apenas fazer-saber (informar) ou fazer-compreender (explicar) um tema científico, mas também incitam o leitor, ao final do texto, a um fazer. Neste trabalho, apresenta-se a análise dos trechos iniciais de quatro artigos extraídos aleatoriamente do total dos 30 do corpo de investigação, a fim de exemplificar o percurso argumentativo realizado pelos divulgadores - os artigos completos selecionados para esta análise estão disponíveis nos Anexos.

Para detalhar as relações textuais, discursivas e epistemológicas presentes, observaram-se o título, o subtítulo e os dois parágrafos iniciais de cada texto, pois nesse trecho ocorrem a introdução do tópico discursivo, a recategoriação do objeto de discurso e a movimentação argumentativa em direção ao saber da ciência. À medida que se constrói o estudo linguístico, vão se observando as ocorrências supracitadas sob o ponto de vista da Epistemologia da Ciência. Para isso, empregam-se três categorias de classificação: o senso comum, a experiência primeira e o conceito científico, conforme propõe Bachelard (1996).

Por fim, para examinar a análise do conjunto, elaboram-se esquemas que ilustram o movimento argumentativo dos trechos. Observe-se que, para facilitar o acompanhamento da análise, numera-se cada período do texto, iniciando pelos títulos, os quais são nomeados de "segmentos".

\section{Análises}

Para proceder às análises, são apresentados a seguir os trechos analisados de cada um dos quatro textos. O texto 1 inicia da seguinte forma: 
(1) Mocinho ou vilão?

(2) Remédios para plantas, defensivos agrícolas, venenos contra pragas... (3) Esses são alguns nomes pelos quais são conhecidos os agrotóxicos, produtos químicos que servem para prevenir, destruir ou controlar diferentes tipos de praga em plantações. (4) Se, por um lado, eles são um escudo para as plantas, por outro, podem causar danos à saúde de animais, e isso inclui de minhocas a seres humanos. (5) Tudo depende da forma como é aplicado no ambiente. [...] (BEL; AROUCA, 2014).

No segmento (1), encontra-se o título do artigo, que apresenta uma disjunção marcada pelo conector ou, a qual se fará presente ao longo do trecho. Indica-se, assim, que se falará de um objeto a que se atribuem características excludentes: ou boas (mocinho) ou más (vilão), sem, no entanto, nomeá-lo. A pergunta presente no título instiga o leitor a saber de que trata, afinal, o artigo. Paralelamente, as alusões aos termos "mocinho" e "vilão" buscam incitar a leitura, pois elas remetem a personagens de histórias de heróis e bandidos que estão na memória do leitor infantil.

O segmento (2), por sua vez, que inicia o corpo do texto, principia a topicalização do discurso, ao trazer os nomes populares do objeto a ser definido no segmento (3), bem como suas funções. Observa-se, também, a construção do objeto de discurso: antecedendo o emprego do termo técnico agrotóxico, aparece sua designação por diversos outros nomes através dos quais ele é conhecido popularmente: remédios para plantas, defensivos agrícolas, venenos contra pragas. Ao utilizar a denominação agrotóxico, o enunciador não invalida as designações iniciais, mas as ressignifica, uma vez que o termo técnico possui uma acepção negativa na sociedade. O aposto que sucede a expressão agrotóxicos, produtos químicos que servem para prevenir, destruir ou controlar diferentes tipos de praga em plantações, procura minimizar a designação desfavorável, apresentando aspectos positivos e negativos.

Do ponto de vista epistemológico, o segmento (2) traz as concepções de senso comum relativas ao objeto, as quais recebem, no segmento (3), a nomeação científica. Essa passagem do senso comum ao científico é abrupta, não havendo nenhuma intermediação entre as duas formas de saber. Na verdade, a nomeação técnica do objeto não invalida as definições iniciais, mas associa tais definições a um termo específico com conotações negativas.

Já os segmentos (4) e (5) exploram a oposição entre bem e mal anunciada no título do artigo. Os articuladores se, por um lado e por outro assinalam o contraste entre 
as características positivas e negativas dos agrotóxicos. $\mathrm{O}$ acréscimo da informação $e$ isso inclui de minhocas a seres humanos concede força argumentativa para a avaliação negativa dos agrotóxicos. O segmento (5), no entanto, procura reorientar essa avaliação, atribuindo a repercussão positiva ou negativa à forma como o veneno é aplicado e não a uma característica inerente ao produto. Apesar disso, o que vai prevalecer no final do artigo (ver Anexos - Texto 1) é a perspectiva negativa sobre o agrotóxico, a ponto de sugerir o consumo de produtos orgânicos ou sem agrotóxicos. Assim, é possível visualizar esse texto a partir do Esquema 1, apresentado a seguir.

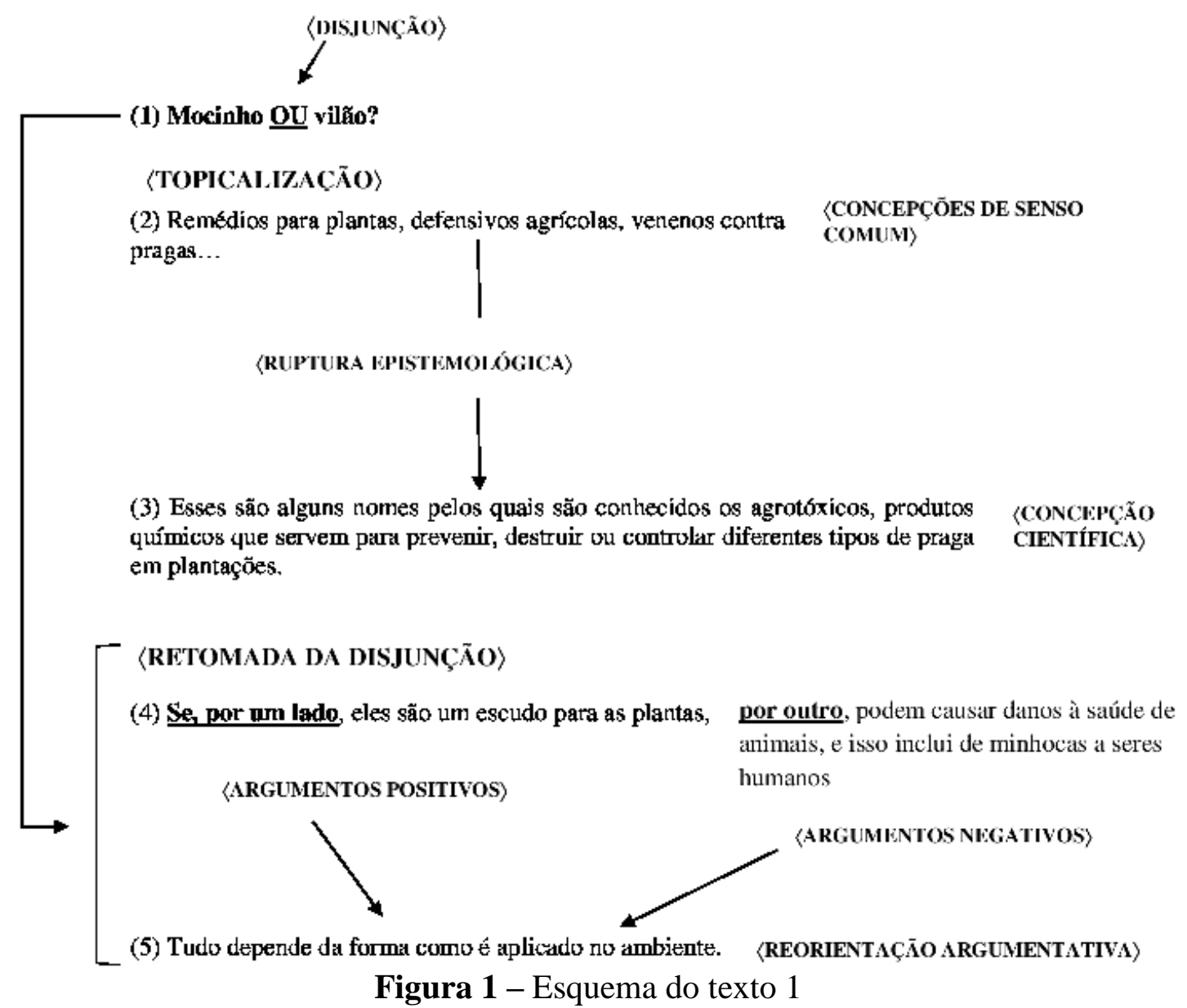

Já o texto 2 inicia da seguinte forma:

(1) Feijão protegido

(2) Grãos brasileiros ficarão guardados em um banco na Noruega por mais de mil anos

(3) Figura certa no prato da maioria dos brasileiros, o feijão viajou de 
mala e cuia para a Noruega. (4) Calma! (5) Você não vai ficar sem um dos principais alimentos do seu almoço. (6) Foram apenas alguns grãos dos tipos de feijão mais consumidos no Brasil que seguiram viagem até o Banco Global de Sementes Svalbard, que fica no país europeu.

(7) Agora... (8) Por que um banco precisa de grãos de feijão? (9) Bom, esse banco não guarda dinheiro, como os tradicionais. (10) Um banco de sementes reúne inúmeros tipos de grãos de todo o mundo. (11) Lá, eles são bem guardados, reservados em embalagens que ficam a uma temperatura de 20 graus negativos para impedir que estraguem. [...] (LUCARINY, 2015).

Um elemento de destaque nesse trecho inicial do artigo é o uso constante de marcas textuais associadas à estruturação de conversação, o que, segundo Adam (2011, p. 188), imprime "uma tonalidade enunciativa e interativa mais marcada". O emprego desses marcadores cria uma aproximação do produtor com o leitor pelo tom coloquial associado às conversas, embora a distância entre eles ainda exista, uma vez que o produtor detém informações que deseja compartilhar com seu leitor. Enquadram-se nesse caso os segmentos: (4) Calma!; (5) Você, não vai ficar sem um dos principais alimentos do seu almoço; (8) Agora...; (9) Bom, esse banco não guarda dinheiro, como os tradicionais; e (11) Lá, eles são bem guardados, reservados em embalagens que ficam a uma temperatura de 20 graus negativos para impedir que estraguem.

O segmento (1), o título, juntamente com o segmento (2), a linha de apoio, traz o tópico do artigo, o feijão, não como um alimento ou uma receita, mas como uma semente a ser guardada em um banco fora do país. Já o segmento (3) desenvolve esse tema, aproximando-o do universo de conhecimento do leitor, que sabe que o feijão é o prato preferido dos brasileiros. A informação nova é a de que alguns grãos dessa leguminosa viajaram para a distante Noruega. Os segmentos (5) e (6), por sua vez, evidenciam que o enunciador reconhece o caráter inesperado dessa informação e que ela pode gerar um sentimento de rejeição. Por isso, há o emprego da interjeição Calma!, uma forma de interação direta que procura minimizar o sentimento negativo que poderia surgir. Ao mesmo tempo, essa pausa objetiva produzir um efeito de suspense e levar o leitor a prosseguir com a leitura, a fim de saber detalhes dessa novidade.

Ainda no segmento (6), inicia-se a explicação sobre a viagem do feijão, com a introdução do nome formal do local para onde as sementes foram levadas. Essa ação discursiva lida com o senso comum sobre a palavra banco, que remete à acepção de instituição financeira. Mas o objeto de discurso banco de sementes precisa ainda ser 
construído como termo técnico, ou seja, como procedimento de armazenagem de sementes, cujo fim é evitar que certas culturas agrícolas desapareçam.

Como mencionado, o segmento (7) traz uma marca da oralidade, assim como a pergunta presente no segmento (8), que explicita um questionamento que poderia ser feito pelo leitor. Para Adam (2011, p. 254), esse processo pode ser considerado uma “dialogização do procedimento descritivo", já que se estabelece como um suposto diálogo entre o autor e o leitor, cuja resposta consiste em uma descrição que esclarece a dúvida. Assim, após a pergunta, surgem os segmentos (9), (10) e (11), que explicitam os diferentes sentidos da palavra banco. Observe-se que, no segmento (9), o enunciador retoma o sentido mais conhecido para negá-lo: Bom, esse banco não guarda dinheiro, como os tradicionais. Em seguida, apresenta-se a definição que reconstrói o objeto de discurso banco, ressignificando-o para o contexto científico de banco de grãos.

Do ponto de vista da epistemologia, o segmento (9) traz a experiência cotidiana, isto é, o senso comum, sobre uso dos bancos como instituições financeiras. No dia a dia, bancos costumam lidar com dinheiro, e não com sementes. No entanto, é preciso ir além desse contexto familiar: "sobre qualquer questão, sobre qualquer fenômeno, é preciso passar primeiro da imagem para a forma geométrica e, depois, da forma geométrica para a forma abstrata" (BACHELARD, 1996, p. 10-11). Desse modo, rompe-se uma imagem concreta de banco em direção ao conceito abstrato, ou seja, de banco como um local de armazenagem de valores dos mais variados tipos, como dinheiro ou sementes, por exemplo. Esse último sentido é explorado nos segmentos (10) e (11).

Na sequência do texto, o divulgador instiga o leitor a pensar sobre a importância da ação de guardar o feijão no Banco Global de Sementes Svalbard, já que se trata de um alimento extremamente popular no Brasil, e, ao final do artigo, convida-o a pensar que outras sementes teriam igual importância e também mereceriam, por isso, ser guardadas nesse Banco. Assim, o texto 2 pode ser esquematizado da seguinte maneira: 
(7) Agora... (8) Por que um banco precisa de grãos de feijão?

(9) Bom, esse banco não guarda dinheiro, como os tradicionais.

$$
\mid
$$

(RUPT URA EPIST EMOLÓGICA)
¿CONCEPÇĂO DE SENSO

COMUM, IMAGEM

CONCRETA)

\begin{abstract}
(10) Um banco de sementes reúne inúmeros tipos de grãos de
todo o mundo. (11) Lá, eles são bem guardados, reservados em
embalagens que ficam a uma temperatura de 20 graus negativos
para impedir que estraguem.
(10) Um banco de sementes reúne inúmeros tipos de grãos de
todo o mundo. (11) Lá, eles são bem guardados, reservados em
embalagens que ficam a uma temperatura de 20 graus negativos
para impedir que estraguem.

(10) Um banco de sementes reúne inúmeros tipos de grãos de
todo o mundo. (11) Lá, eles são bem guardados, reservados em
embalagens que ficam a uma temperatura de 20 graus negativos
para impedir que estraguem.

(10) Um banco de sementes reúne inúmeros tipos de grãos de
todo o mundo. (11) Lá, eles são bem guardados, reservados em
embalagens que ficam a uma temperatura de 20 graus negativos
para impedir que estraguem.
\end{abstract}

Figura 2 - Esquema do texto 2

\section{¿CONCE PÇĂO CIE NTÍFICA, SENT IDO ABST RAT O)}

O terceito texto analisado neste estudo inicia assim:

(1) Por que algumas pessoas têm bruxismo?

(2) Se pensou em dom para feitiçaria, pode esquecer. (3) Bruxismo não tem nada a ver com isso! (4) Costuma ser resultado de um problema de saúde que leva as pessoas a ranger os dentes sem querer, principalmente durante o sono. (5) $\mathrm{O}$ ranger pode ser tão forte que a pessoa acorda com dor no queixo e, com o passar do tempo, pode ter os dentes desgastados.

(6) Mas o que pode causar o bruxismo? (7) Na verdade, existem vários fatores, um deles está nos próprios dentes. (8) Pessoas com os dentes fora do lugar, com má oclusão, ou seja, com uma mordida que não encaixa direito, têm mais chance de desenvolver o bruxismo. (9) A falta de vitaminas e nutrientes no organismo, alergias e problemas respiratórios também podem fazer surgir o bruxismo. [...] (ALMEIDA, 2014, p. 14).

No artigo 3, o segmento (1) introduz o tópico discursivo do texto sob a forma de pergunta: por que algumas pessoas têm bruxismo? A indagação carrega um pressuposto, o de que há pessoas que têm bruxismo, assinalando o tópico do discurso. Mas o que vem a ser bruxismo? Nesse sentido, o segmento (2) estabelece a suposição de que o leitor poderia ter relacionado bruxismo à bruxaria, devido ao radical comum às duas palavras. A associação é negada firmemente pela expressão coloquial pode 
esquecer. Em (3), o enunciador nega explicitamente essa hipótese: Bruxismo não tem nada a ver com isso.

Essa construção associativa pode ser considerada uma forma de elaboração do senso comum, segundo a epistemologia. Trata-se, conforme Bachelard (1996, p. 91), de uma "extensão abusiva das imagens usuais" ou de "considerar um caso em que uma única imagem, ou até uma única palavra constitui toda a explicação". Ou seja, a aproximação entre os dois termos - bruxismo e bruxaria - acontece não só devido à semelhança dos vocábulos pelo radical comum, mas também em função do peso conceitual da palavra bruxa. No entanto, para chegar à definição de bruxismo, é preciso romper com essa impressão inicial causada pela aparência das palavras.

Após a ruptura, é necessário imediatamente definir o tópico bruxismo, o que se realiza nos segmentos (4) e (5), nos quais se define o nome como um termo da área médica. Na verdade, esse distúrbio do sono popularmente conhecido como bruxismo é designado, na medicina, como briquismo ou bricomania, termo derivado do grego brychein, que significa ranger de dentes (MACEDO, 2008). É plausível que o nome bruxismo tenha se fixado devido a uma aproximação fonética com a pronunciação bruccismo. Em um artigo destinado a crianças, o tópico, no entanto, é o nome popular: o bruxismo.

No parágrafo seguinte, com vistas a fornecer explicações, apresentam-se as causas de tal fenômeno. Assim, após definido o termo do ponto de vista da ciência, segue a explanação. Observe-se o emprego do conector mas no segmento (6), que marca justamente a entrada de um subtópico: a definição para as causas do problema. Após a modalização realizada por meio do operador na verdade presente no segmento (7), citam-se, em (7), (8) e (9), os fatores causadores do bruxismo. O emprego do na verdade mostra que se declara ali o ponto de vista da ciência.

$\mathrm{Na}$ sequência do texto, o divulgador sugere ao leitor que, se este sente os sintomas descritos, procure um profissional especializado: um dentista, para resolver o problema de dentição, e um psicólogo, a fim de entender melhor a situação desagradável, mas temporária, que enfrenta. Com base nisso, é possível compreender o texto 3 pelo esquema apresentado a seguir. 
(1) Por que algumas pessoas têm bruxismo?<smiles>C=CC</smiles>

(2) Se pensou em dom para feitiçaria, pode esquecer.

(3) Bruxismo não tem nada a ver com isso!

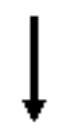

(4) Costuma ser resultado de um problema de saúde que leva as pessoas a ranger os dentes sem querer, principalmente durante o sono.

(5) $O$ ranger pode ser tão forte que a pessoa acorda com dor no queixo $\mathrm{e}$, com o passar do tempo, pode ter os dentes desgastados.

\section{(MUDANÇA DE T ÓPICO, CAUSAS)}

(6) Mas o que pode causar o bruxismo?

(7) $\mathrm{Na}$ verdade, existem vários fatores, um deles está nos próprios dentes. (8) Pessoas com os dentes fora do lugar, com má oclusão, ou seja, com uma mordida que não encaixa direito, têm mais chance de desenvolver o bruxismo. (9) A falta de vitaminas e nutrientes no organismo, alergias e problemas respiratórios também podem fazer surgir o bruxismo.

Figura 3 - Esquema do texto 3

\author{
¿CONCEPÇĂO \\ CIENT ÍFICA, \\ DEFINIÇĂO)
}

\section{¿ CONCEPCCĂO CIENT ÍFICA, CAUSAS)}

O último texto selecionado para análise, começa da seguinte maneira:

(1) Você sabia que existem super-raios?

(2) "Não há duas pessoas iguais", diz o velho ditado. Pois com os raios acontece a mesma coisa. (3) Assim como existem pessoas diferentes, existem raios mais fortes do que outros. (4) Alguns são tão mais fortes que a média de intensidade dos comuns que acabaram ganhando o nome de super-raios!

(5) Você com certeza já viu raios em dia de tempestade, mas talvez não saiba que eles são correntes elétricas similares às que circulam nos fios dos aparelhos que temos em casa - só que bem mais intensas. (6) E, em vez de passar por um fio, o raio ocorre na atmosfera. [...] (PINTO JUNIOR, 2015).

O título em forma de pergunta, no segmento (1), já apresenta o tópico do artigo: a existência de super-raios. Na continuidade, o divulgador procura responder à questão colocada.

Iniciando o corpo do texto, o segmento (2) traz um ditado popular que tematiza as diferenças individuais entre as pessoas. Sobre essa base, constrói-se uma analogia com os raios, desenvolvida no segmento (3), que explicita a existência de raios mais 
fortes do que outros. No segmento (4), por sua vez, segue a comparação por superioridade. O enunciador marca, porém, que a potência dessa superioridade é extrema, o que justifica a nomeação escolhida: super-raios.

Nos segmentos (5) e (6), estabelece-se cientificamente o que são os raios. No entanto, em vez de o enunciador definir diretamente o objeto, prefere criar novamente uma forma de aproximação com o leitor, no segmento (5), por meio do uso do você e da afirmação de um dado tido como óbvio - todo mundo já viu raios. Essa asserção é complementada pela explicação formal sobre o que eles são. Observe-se o emprego do conector argumentativo mas, cuja função é reorientar o discurso e conduzir o leitor para uma abordagem científica do tema, que liga o raio a correntes elétricas. Chama a atenção, nesse sentido, a comparação com um conhecimento suposto do leitor, o de que as correntes elétricas circulam nos fios dos aparelhos domésticos.

Nesse segmento, fica bastante evidente a abordagem epistemológica, em que se parte da experiência vivencial ou primeira, para, em seguida, reformulá-la com base na definição científica. É importante salientar que o conhecimento prévio, nesse caso, consiste em uma experiência visual, auditiva e emocional (MEDEIROS, A.; MEDEIROS, C., 2011), uma vez que os raios suscitam muitas impressões devido às suas características associadas: luz intensa, estrondo, danos materiais e possibilidade de ferimentos e morte.

Cabe destacar, ainda, que a ação discursiva de reorientação vem marcada pelo índice de modalidade (KOCH, 2013) talvez (em talvez [você] não saiba), o que modaliza o suposto saber do leitor pela incerteza. Essa escolha de inserir a dúvida sobre se o leitor teria ou não aquele conhecimento produz um efeito de aproximação, já que, ao mesmo tempo em que respeita o destinatário que desconhece esse saber, não desvaloriza aquele que já aprendeu o tema em outras instâncias. No entanto, a comparação por semelhança sofre uma restrição: só que bem mais intensas. O operador de uso informal só que marca, assim, a contraposição que assinala a diferença de intensidade entre as correntes. O segmento (6), iniciado pelo conector de conjunção $e$, indica a soma de um argumento fundamental para diferenciar os raios das correntes elétricas: os raios acontecem na atmosfera, ao passo que as correntes necessitam da presença de um fio para que sejam conduzidas. 
Ao final do artigo, o divulgador lembra o leitor de que, a partir do conhecimento adquirido, ele pode apreciar o espetáculo dos raios durante tempestades de forma diferenciada, já que sabe como eles se formam e quais são os efeitos negativos e positivos que ocasionam à natureza e aos seres humanos. É possível, a partir disso, realizar a seguinte esquematização do tex to 4 :

(5) Você com certeza já viu raios em dia đe tempestade, (EXPERIÊNCLA SEN SORIAL) mas talvez (REORIENTAÇĂO ARGUMENT AT IVA) não saiba que eles são correntes elétricas similares às que circulam nos fios dos aparelhos que temos em casa

\section{(CONCE PÇĂO CIENT ÍFICA)}

\section{〈RESTRICĂO}

- só que bem mais intensas.

\section{(ARGUMENT AÇĂO)}

(6) $\underline{\mathbf{E}}$, em vez de passar por um fio, o raio ocorre na atmosfera.

Figura 4 - Esquema do texto 4

\section{Discussão dos resultados}

Embora se observem diferentes estratégias de aproximação com o leitor, há algo em comum nos textos analisados: a necessidade de se partir de algo conhecido para, então, trazer o conhecimento científico de uma maneira direta, sem intermediários ou negociações, de forma a gerar instabilidade no leitor. Para atingir esse objetivo, o texto 1 colocou, no título, ou seja, antes mesmo de expor o tópico discursivo, a disjunção entre o bem e o mal no que se refere aos agrotóxicos, objeto que foi anunciado por meio das diversas expressões que lhe são atribuídas no dia a dia: remédios para plantas, defensivos agrícolas, venenos contra pragas. Observe-se que elas minimizam o efeito negativo do produto causado nas pessoas e mostram nomeações que salientam somente sua atuação sobre as plantas. Em seguida, houve a denominação e a definição científica do tópico - agrotóxico -, situado como um termo relacionado a diversos problemas, inclusive à saúde humana e animal. Dessa forma, o que o senso comum considerou inofensivo, do ponto de vista da ciência, é apresentado como um produto químico perigoso, que pode trazer danos ao leitor. 
Já no texto 2, destacam-se duas estratégias do divulgador: a valorização do inusitado - a viagem do feijão - e o uso do termo banco, sem que seja esclarecido de antemão seu significado. Ou seja, a construção do senso comum está relacionada ao conceito de banco somente como instituição financeira e não como um local de armazenamento de valores, quaisquer que sejam eles. Após, o divulgador dialoga com o leitor sobre o estranhamento que as informações iniciais podem ter causado. Em seguida, vêm as devidas explicações sobre as afirmativas iniciais, desfazendo-se qualquer possibilidade de confusão.

O texto 3, por sua vez, teve como viés epistemológico a semelhança entre palavras - bruxa e bruxismo, o que levou a um prolongamento forçado de sentido. Em um primeiro movimento, o divulgador buscou romper com essa dinâmica, para, então, construir o sentido técnico da palavra bruxismo, com as devidas explicações científicas sobre suas causas.

O texto 4 partiu de uma analogia para tratar de uma experiência sensorial comum ao leitor e construiu uma espécie de negociação em torno do conceito, ao assumir que parte das informações já pode ser de conhecimento do leitor, tendo o cuidado, porém, de não excluir aquele leitor que, por acaso, não possuísse esse saber. $\mathrm{O}$ movimento argumentativo é marcado textualmente pelos índices de modalidade já apontados - com certeza e talvez -, que indicam o cuidado para não afastar nenhum tipo de interlocutor. Esse procedimento se apoia no fato de que os raios são muito comuns na vida das pessoas e que sempre existe alguma explicação para sua ocorrência. Assim, é preciso intervir de maneira a valorizar os conhecimentos prévios, ao mesmo tempo em que se oferece a explicação científica necessária.

Em todos os textos analisados acontece, dessa forma, um salto do que é conhecido para a novidade, isto é, para o saber científico. Essa passagem do não científico ao científico é abrupta, sem intermediários e sem ajustes, o que causa uma sensação de lacuna e de falta, exigindo uma solução. Se a explicação correta não é aquela conhecida pelo senso comum, qual seria essa explicação, então? A estratégia discursiva procura criar, assim, um desejo de saber, o que é designado por Bachelard (1994, p. 18) de "vontade de intelectualidade". Observe-se que o locutor não nega o senso comum, como se o leitor fosse uma folha em branco no que concerne aos conhecimentos sobre o tema em questão, mas reconhece a existência de um saber 
anterior que circula na sociedade. Estabelece-se, então, um espaço conceitual entre o que o leitor já sabe, e a novidade trazida pela informação, o que gera o vazio a ser preenchido pelo conhecimento científico.

Ainda dentro da abordagem epistemológica, pode-se afirmar que a inserção do novo saber mostra uma diferente maneira de compreender um tema. Nesse sentido, a troca que se estabeleceu também envolve o entendimento de que os conhecimentos não são simplesmente cumulativos e justapostos, mas estão sujeitos a mudanças complexas, que envolvem, muitas vezes, o abandono de uma concepção em favor de outra mais elaborada, bem como o entendimento dos limites de um dado modelo explicativo.

Outro resultado significativo sobre a linguagem diz respeito às marcas explícitas de oralidade, presentes, com maior ou menor intensidade, em todos os trechos analisados, o que acaba gerando um diálogo entre locutor e interlocutor. Uma estratégia utilizada para realizar essa interlocução foi explicitar perguntas ao longo do texto, em uma aproximação com a linguagem das crianças, que, como se sabe, estão constantemente questionando. $\mathrm{Na}$ verdade, não se tratou apenas de uma estratégia textual de aproximação, mas também de uma maneira de identificação dos obstáculos epistemológicos, ou seja, de apontamento e esclarecimento de conflitos entre o senso comum e a novidade do conhecimento científico. Não houve, porém, em nenhum momento, uma desqualificação do que foi aprendido pelo senso comum, mas somente sua delimitação.

Além disso, como afirma Bachelard: "E, digam o que disserem, na vida científica os problemas não se formulam de modo espontâneo. [...] Para o espírito científico, todo conhecimento é resposta a uma pergunta" (1996, p. 18). Os textos apresentados divulgam um conhecimento estruturado em torno de questionamentos da realidade; nada mais natural, assim, que trazer tais questionamentos para dentro do texto como uma forma de mostrar que a ciência pode nascer de reflexões sobre o cotidiano e não somente em grandes laboratórios de pesquisa. 


\section{Conclusões}

Retoma-se aqui o que foi proposto no título deste artigo: a sedução da ausência. Essa conjectura foi esclarecida pela confluência da Linguística e da Epistemologia, ao se descrever a instauração, pelo divulgador, de um espaço vazio entre o conhecimento científico do locutor e o conhecimento de senso comum do interlocutor. Essa ação tem duplo objetivo: o de fazer com que o texto seja consumido até o fim e o de proporcionar, ao mesmo tempo, a apropriação das informações oriundas da ciência. Justificou-se o estabelecimento desse processo pela necessidade tácita do ser humano de adquirir conhecimento, descrita como vontade de intelectualidade.

Os resultados indicam que a LT oferece instrumental teórico para evidenciar esses movimentos discursivos e que as categorias epistemológicas selecionadas trouxeram fundamentos para compreender a estruturação do conhecimento científico, tal como foi proposto por Bachelard (1996). Ressalta-se, ainda, que não existiu a pretensão de lidar com os questionamentos sobre o que vem a ser um bom texto de divulgação científica. Na verdade, instaurou-se uma outra pergunta: uma vez que os textos estão postos, como eles atendem à expectativa/necessidade de divulgar ciência para as crianças? Os resultados obtidos mostram que, pelo menos de um ponto de vista textualdiscursivo e epistemológico, a CHC procura atingir alguns dos objetivos delimitados pela divulgação científica para crianças, isto é, a revista busca aproximar o conteúdo científico de seus leitores, ao criar estratégias para uma efetiva apropriação do conhecimento por meio da crítica ao senso comum e do estabelecimento do conceito científico.

É importante considerar que, embora este estudo tenha sido realizado com textos da CHC que têm um fim discursivo comum - o de levar o leitor a uma ação -, acreditase que esse tipo de construção argumentativa/epistemológica não seja incomum em textos de DCM em diferentes veículos, já que frequentemente eles iniciam apresentando elementos próximos do leitor: uma imagem, uma ação cotidiana ou uma observação casual. Nesse sentido, a hipótese para explicar a frequência desse tipo de organização textual na DCM, um plano de texto conforme Adam (2011), está associada com a necessidade dos textos publicados no domínio midiático de assinalar uma fundamental diferença em relação à maneira didática de lidar com temas da ciência: no domínio 
didático, por razões contratuais, não se leva em conta o conhecimento do leitor e se estabelece um distanciamento significativo entre os interlocutores.

FUKUI, Ana; GIERING, Maria Eduarda. The Seduction of Absence: text and epistemology of Science. Revista do Gel, São Paulo, v. 13, n. 3, p. 176-202, 2016.

\begin{abstract}
This study aims to demonstrate the way the textual producer organizes the transition from the common sense to the scientific knowledge in scientific popularization articles written for children and published in the magazine Ciência Hoje das Crianças (CHC). For this purpose, based on Discourse Textual Analysis, we analyze the title and the initial paragraphs of the articles, observing the way the installment of the discursive topic, the construction of discourse objects and the argumentative orientation occur. The linguistic analysis proposed is enlightened by principles of Scientific Epistemology, by Bachelard, which guide the producer-publisher of science. We observe that the text is organized in order to unleash a process of argumentative orientation that goes from a common knowledge to the installment of the scientific knowledge, which is the base of the discursive aim of incitement to an action, common among the articles that compose the corpus. We verify that $\mathrm{CHC}$ seeks to bring its readers and the scientific content closer, by creating strategies toward an effective knowledge appropriation by means of the criticism to the common sense and of the establishment of scientific concepts.
\end{abstract}

Keywords: Scientific popularization. Children. Argumentative orientation. Ciência Hoje das Crianças. Scientific Epistemology.

Submetido em: 19/05/2016.

Aceito em: 28/06/2016.

\title{
Referências
}

ADAM, J.-M. A Linguística Textual: introdução à análise textual dos discursos. 2. ed. São Paulo: Cortez, 2011.

ALMEIDA, J. R. Por que algumas pessoas têm bruxismo? Ciência Hoje das Crianças, Rio de Janeiro, n. 262, p. 14, 2014.

APOTHÉLOZ, D.; REICHLER-BÉGUELIN, M. J. Construction de la référence et stratégies de désignation. In: BERRENDONNER, A.; REICHLER-BÉGUELIN, M-J. (orgs.). Du sintagme nominal aux objects-de-discours: SN complexes, nominalizations, anaphores. Neuchâtel: Institute de linguistique de l'Université de Neuchâtel, 1995. p. 227-271. 
BACHELARD, G. Psicanálise do Fogo. São Paulo: Martins Fontes Editora, 1994.

A Formação do Espírito Científico. Rio de Janeiro: Contraponto, 1996.

BEL, M.; AROUCA, S. Mocinho ou vilão? Ciência Hoje das Crianças, Rio de Janeiro, nov. 2014. Disponível em: <http://chc.cienciahoje.uol.com.br/mocinho-ouvilao-2/>. Acesso em: 20 abr. 2016.

CAVAlCAnTe, M. M.; CUStódio Filho, V.; BRITO, M. A. P. Coerência, referenciação e ensino. São Paulo: Cortez, 2014.

CHARAUDEAU, P. O discurso propagandista: uma tipologia. In: MACHADO, I. L.; MELLO, R. Análises do Discurso Hoje. Rio de Janeiro: Nova Fronteira, Lucerna, 2010. p. 57-78.

GIERING, M. E. O discurso promocional em artigos de divulgação científica midiática para jovens leitores. Revista Bakhtiniana, São Paulo, v. 11, n. 2, p. 52-68, mai./ago. 2016. Disponível em: <http://revistas.pucsp.br/index.php/bakhtiniana/article/view/23516/19234>. Acesso em: 03 mai. 2016.

JUBRAN, C. C. A. S. Revisitando a noção de tópico discursivo. Cadernos de Estudos Lingüísticos, Campinas, v. 48, n. 1, ago. 2011. ISSN 2447-0686. Disponível em: <http://periodicos.sbu.unicamp.br/ojs/index.php/cel/article/view/8637253/4975>.

Acesso em: 17 mai. 2016. Doi: <http://dx.doi.org/10.20396/cel.v48i1.8637253>.

KOCH, I Introdução à Linguística Textual. 2. ed. São Paulo: WMF Martins Fontes, 2009.

A Inter-ação pela linguagem. 11. ed. São Paulo: Contexto, 2013.

As Tramas do Texto. 2. ed. São Paulo: Contexto, 2014.

KUHN, T. A Estrutura das Revoluções Científicas. São Paulo: Perspectiva, 1992.

LUCARINY, L. Feijão protegido. Ciência Hoje das Crianças, Rio de Janeiro, abr. 2015. Disponível em: <http://chc.cienciahoje.uol.com.br/feijao-protegido/>. Acesso em: 20 abr. 2016.

MONDADA, L.; DUBOIS, D. Construction des objets de discours et catégorisation: une approche des processus de référenciation. Travaux Neuchâtelois de Linguistique (TRANEL), v. 23, p. 273-302, 1995.

MACEDO, C. R. de. Bruxismo do sono. Revista Dental Press de Ortodontia e Ortopedia Facial, Maringá, v. 13, n. 2, p. 18-22, mar./abr. 2008.

MARCUSCHI, L. A. Referenciação e Progressão Tópica: Aspectos Cognitivos e Textuais. Cadernos de Estudos Linguísticos, Campinas, v. 48, n. 1, p. 7-22, 2006. 
Disponível em: <http://revistas.iel.unicamp.br/index.php/cel/article/view/1539>. Acesso em: 11 mai. 2016.

MASSARANI, L. (Ed.). Ciência e criança: a divulgação científica para o público infantojuvenil. Rio de Janeiro: Fiocruz, 2008.

MEDEIROS, A.; MEDEIROS, C. Os raios no imaginário popular. Revista Brasileira de Pesquisa em Educação em Ciência, Rio de Janeiro, n. 3, p. 84-96, 2011. Disponível em: <http://www.nutes.ufrj.br/abrapec/iiienpec/Atas\%20em\%20html/o98.htm>. Acesso em: 25 abr. 2016.

PINTO JUNIOR, O. Você sabia que existem super-raios? Ciência Hoje das Crianças, Rio de Janeiro, abr. 2015. Disponível em: <http://chc.cienciahoje.uol.com.br/vocesabia-que-existem-super-raios/>. Acesso em: 20 abr. 2016.

POPPER, K. A Lógica da Pesquisa Científica. São Paulo: Cultrix, 2006. 


\section{ANEXOS - textos completos da CHC}

\section{Texto 1:}

\section{Mocinho ou vilão?}

Remédios para plantas, defensivos agrícolas, venenos contra pragas... Esses são alguns nomes pelos quais são conhecidos os agrotóxicos, produtos químicos que servem para prevenir, destruir ou controlar diferentes tipos de praga em plantações. Se, por um lado, eles são um escudo para as plantas, por outro, podem causar danos à saúde de animais, e isso inclui de minhocas a seres humanos. Tudo depende da forma como é aplicado no ambiente.

Os agrotóxicos podem ser usados em vasos de planta, jardins, pequenas roças ou grandes plantações com o propósito de evitar que microrganismos, e também plantas daninhas, prejudiquem o crescimento dos vegetais.

Então, vejamos, se os agrotóxicos agem pelo bem dos vegetais, eles são ótimos, certo? Nem sempre. Muitas vezes você vê na feira aqueles legumes, verduras e frutas parecerem mais bonitos para conseguir um preço melhor e, para isso, muitos usam agrotóxicos além da conta. Os resultados disso são: dano à saúde do trabalhador rural, que, em geral, aplica o produto sem proteção; dano à saúde do consumidor, que ingere vegetais contaminados; e dano ao meio ambiente, pela poluição do solo e das águas, que prejudica das minhocas aos peixes.

E aí, o que fazer? Se você tiver algum receio na hora de fazer a feira, procure comprar os vegetais de produtores que você conheça para evitar consumir produtos contaminados. Outra opção é comprar produtos identificados na embalagem como orgânicos. Esta denominação é garantia de que não são produzidos com o uso de agrotóxicos. É melhor prevenir...

Por conta do risco que os agrotóxicos podem representar, cabe aos cientistas a tarefa de pesquisar outras formas de combater as pragas das plantações. Da mesma forma, cabe aos órgãos competentes a fiscalização dos produtores agrícolas para punir quem desobedece aos limites de utilização dos agrotóxicos, prejudicando as pessoas e o meio ambiente. 


\section{Texto 2:}

\section{Feijão protegido}

\section{Grãos brasileiros ficarão guardados em um banco na Noruega por mais de mil anos}

Figura certa no prato da maioria dos brasileiros, o feijão viajou de mala e cuia para a Noruega. Calma! Você não vai ficar sem um dos principais alimentos do seu almoço. Foram apenas alguns grãos dos tipos de feijão mais consumidos no Brasil que seguiram viagem até o Banco Global de Sementes Svalbard, que fica no país europeu.

Agora... Por que um banco precisa de grãos de feijão? Bom, esse banco não guarda dinheiro, como os tradicionais. Um banco de sementes reúne inúmeros tipos de grãos de todo o mundo. Lá, eles são bem guardados, reservados em embalagens que ficam a uma temperatura de 20 graus negativos para impedir que estraguem.

O Banco Global de Sementes Svalbard tem capacidade para armazenar cerca de 4,5 milhões de amostras de sementes e é considerado o mais seguro do mundo sementes guardadas lá podem resistir por mais de mil anos. O local é protegido contra terremotos, enchentes e explosões nucleares.

Tanta preocupação com as sementes tem um motivo. Se, por alguma razão, uma semente importante para o homem (como o feijão) desaparecer, é só ir no banco e resgatá-la, intacta e pronta para germinar.

Por que o feijão?

Segundo o engenheiro agrônomo Paulo Hideo, da Empresa Brasileira de Pesquisa Agropecuária, o feijão foi escolhido pela sua importância no país. "É um alimento muito popular, todo mundo come", explica. "Além disso, é barato, de fácil acesso, e oferece a quem o consome nutrientes e proteínas essenciais. Junto com o arroz é um alimento completo!"

Se você só gosta de um tipo específico de feijão, não se preocupe. Segundo o pesquisador, vários tipos do grão foram enviados para agradar a todos os gostos. "Enviamos feijão preto, manteiga, carioca e muitos outros", conta. E o parceiro principal do feijão, o arroz, também está a salvo, bem como o milho.

E você, que outras sementes acha que precisam ser protegidas? 


\section{Texto 3:}

\section{Por que algumas pessoas têm bruxismo?}

Se pensou em dom para feitiçaria, pode esquecer. Bruxismo não tem nada a ver com isso! Costuma ser resultado de um problema de saúde que leva as pessoas a ranger os dentes sem querer, principalmente durante o sono. O ranger pode ser tão forte que a pessoa acorda com dor no queixo e, com o passar do tempo, pode ter os dentes desgastados.

Mas o que pode causar o bruxismo? Na verdade, existem vários fatores, um deles está nos próprios dentes. Pessoas com os dentes fora do lugar, com má oclusão, ou seja, com uma mordida que não encaixa direito, têm mais chance de desenvolver o bruxismo. A falta de vitaminas e nutrientes no organismo, alergias e problemas respiratórios também podem fazer surgir o bruxismo.

Problemas emocionais - como tristeza, ansiedade e medo constante - são outra razão para as pessoas começarem a ranger os dentes sem se dar conta. Quer mais? Pois esse problema pode ainda ser herdado. Isso quer dizer que pais que tinham bruxismo podem ter filhos que o repitam.

Se você acorda com a boca dolorida, conte a um adulto de sua confiança e peça para ir ao dentista. Detectar o problema cedo faz toda a diferença na hora de tratá-lo. Uma das medidas mais adotadas para controlar o bruxismo é usar um aparelho com o formato de sua mordida para proteger os dentes durante o sono. Essa medida reduz o desgaste dos dentes e alivia as dores musculares. Também pode ser importante conversar com um psicólogo para ter mais tranquilidade e entender melhor essa situação que é desagradável, mas temporária. 


\section{Texto 4:}

\section{Você sabia que existem super-raios?}

"Não há duas pessoas iguais", diz o velho ditado. Pois com os raios acontece a mesma coisa. Assim como existem pessoas diferentes, existem raios mais fortes do que outros. Alguns são tão mais fortes que a média de intensidade dos comuns que acabaram ganhando o nome de super-raios!

Você com certeza já viu raios em dia de tempestade, mas talvez não saiba que eles são correntes elétricas similares às que circulam nos fios dos aparelhos que temos em casa - só que bem mais intensas. E, em vez de passar por um fio, o raio ocorre na atmosfera.

A intensidade média de um raio equivale a mil vezes a corrente elétrica que circula pelo fio de um chuveiro elétrico. Logo, se em casa devemos ter cuidados para não levar um choque no meio do banho, imagine o que seria um choque provocado por um raio! Ou pior, por um super-raio, que é de 10 a 20 vezes mais forte do que os raios que costumam ocorrer na atmosfera, e ainda mais brilhante!

Os locais atingidos por super-raios costumam sofrer com grandes estragos aos equipamentos eletroeletrônicos ligados na tomada. Dependendo da situação, eles até provocam a morte das pessoas. Mas super-raios são raros. A cada ano, cerca de 50 deles ocorrem no sudeste do Brasil, enquanto são registrados cerca de três milhões de raios comuns na mesma região.

Para quem pensou que os super-raios só causam destruição, uma boa notícia: as descargas elétricas produzidas por eles também têm um lado bom. Colaboram, por exemplo, com a produção de alimentos, porque quebram moléculas de ar, produzindo compostos que, levados ao solo pelas chuvas, ajudam a fertilizá-lo. Esses mesmos compostos, por reações químicas, formam o ozônio - um gás tóxico na superfície da Terra, mas que nos protege dos raios solares quando sobe para a atmosfera.

Agora, quando surgir uma tempestade, você pode observar o céu com outros olhos. Mas lembre-se de fazer isso de dentro de casa, próximo à janela, mas sem tocar nela, porque, caso um raio caia próximo da sua residência, o metal pode conduzir eletricidade e dar choque. 